\title{
Governo Collor: 0 Reformismo Liberal e a Nova Orientação da Política Externa Brasileira*
}

\author{
Brasilio Sallum Jr.
}

Professor titular do Departamento de Sociologia da Universidade de São Paulo (USP). São Paulo, SP. Brasil (e-mail: brasiliosallum@gmail.com)

\begin{abstract}
A liberalização econômica ocorrida na América Latina a partir dos A anos 1980 e, especialmente, na década de 1990, foi entendida como um processo de expansão do capitalismo a partir de seu núcleo em direção à periferia do sistema. Depois da queda do Muro de Berlim e do colapso da União Soviética, tornou-se predominante a interpretação de que tais alterações atingiriam aos poucos todas as sociedades e as fariam convergir para um mesmo padrão de organização econômica, pautado pelo mercado. Reeditava-se com isso, de outra forma, a perspectiva da "modernização", dominante nos anos 1950. As pressões das grandes transnacionais e das "reformas liberais" tenderiam a incorporar todos os países a um mesmo padrão institucional, fazendo com que passassem de não integrados para "superficialmente integrados" e, depois, para "profundamente integrados" (Haggard, 1995; Omahe, 1991). Em relação à América Latina esta interpretação ganhou até uma versão entusiástica: diversos países latino-americanos estariam passando, na expressão de Sebastian Edwards, "from dispair to hope", na medida em que abandonavam os modelos de substituição de importações e os ensaios heterodoxos de gestão econômica em favor de uma orientação mais amigável em relação ao mercado e de políticas econômicas ortodoxas (Edwards, 1994).
\end{abstract}

\footnotetext{
* Este artigo resulta de uma pesquisa apoiada pelo Conselho Nacional de Desenvolvimento Científico e Tecnológico (CNPq). Agradeço a Tullo Vigevani pelas sugestões feitas à primeira versão do texto.

DADOS - Revista de Ciências Sociais, Rio de Janeiro, vol. 54, nํ2, 2011, pp. 259 a 288.
} 
Esta interpretação do processo de liberalização foi combatida por um conjunto de autores que questionaram de várias maneiras a perspectiva da "convergência" procurando demonstrar que, apesar da onda liberalizante, se manteriam diferenças importantes na organização das empresas e do mercado de trabalho, na relação entre Estado e mercado, no plano cultural e assim por diante (Berger e Dore, 1996). Esta literatura crítica em relação ao mainstream ensinou muito sobre a dinâmica diferenciada do capitalismo mundial e fez recuar, na medida em que se passava do século $X X$ para o XXI, a nova teoria da modernização. $O$ avanço econômico da periferia asiática, especialmente da China, onde o peso da intervenção estatal é enorme, contribuiu muito para isso.

A literatura de ciências sociais sobre a liberalização econômica no Brasil não teve evolução similar. A par das reconstruções do processo de liberalização como processo progressivo, interrompido de quando em quando por obstáculos políticos ${ }^{1}$, as versões críticas tendem a vê-lo de forma similar, embora com sinais avaliativos diversos. Na versão crítica, o reformismo liberal tem sido sistematicamente identificado com o neoliberalismo e este com a acentuação dos males do capitalismo na periferia, o baixo crescimento, a exclusão social, a desorganização política das classes subalternas e assim por diante (Boito Jr., 1999; Filgueras, 2000). Embora esta literatura de oposição faça reconstruções pertinentes de algumas dimensões do processo de liberalização, ela uniformiza demais o processo e perde de vista certas especificidades que diferenciam o Brasil, de forma marcante, de outras sociedades latino-americanas de grande porte, como a Argentina e o México.

As interpretações parecem-me particularmente simplistas em relação ao governo Collor (1990-1992), identificado, usualmente, como o marco zero do processo de liberalização no Brasil. Provavelmente a rejeição política e moral que acabou resultando no impeachment do presidente tenha contribuído para esta avaliação unilateral daquele governo. De qualquer modo, os equívocos interpretativos não apenas prejudicam nossa compreensão do passado; também dificultam nosso entendimento do presente, das diferenças que temos em relação a outros países, particularmente os latino-americanos, e das pretensões internacionais do Brasil.

Este artigo pretende contribuir para alterar a interpretação predominante em relação ao reformismo liberal do governo Collor, mostrando 
que ele não se confundia com o neoliberalismo e sublinhando as conexões entre sua face doméstica e sua face internacional.

Ao assumir a Presidência da República em 15 de março de 1990, Fernando Collor recebeu do presidente anterior, José Sarney, um poder alicerçado em um Estado extremamente fraco, seja em relação aos poderes baseados no mercado seja em relação aos centros de poder político mundial. Em sua face externa, o Estado brasileiro mantinha relações conflagradas com os principais centros de poder político do mundo capitalista, em função da moratória da dívida externa brasileira, da política protecionista em relação ao mercado doméstico e do Brasil ter uma política externa refratária aos regimes internacionais caros ao "Ocidente". Estava o Brasil também à margem dos fluxos de capital externo, principalmente os financeiros. Em sua face interna, o Estado carregava uma dívida interna considerável, mostrava-se incapaz de assegurar o valor da moeda (o país estava no limite da hiperinflação, com os preços elevando-se cerca de $80 \%$ ao mês) e perdera também capacidade de impulsionar o desenvolvimento, por causa das dificuldades fiscais e porque o setor público empresarial se tornara pouco eficiente.

Além de fragilizado em relação ao mercado e seus agentes, o Estado não dispunha desde 1983-1984 de objetivos consensuais para a ação providos pelas elites políticas e econômicas brasileiras. Com efeito, no momento da eleição de Fernando Collor, o Brasil ainda experimentava a crise de hegemonia desencadeada no começo da década. A face positiva da crise foi um processo de democratização vigoroso que culminou, do ponto de vista normativo, na aprovação de uma nova Constituição em 1988. E, embora esta carta constitucional tivesse dado ao país uma norma política reguladora, ainda era muito grande a incerteza política sobre os rumos a seguir. Os diversos atores políticos - partidos e outros atores coletivos - que disputavam a direção do Estado orientavam-se não apenas por diferentes interesses, mas também por distintas utopias econômicas e políticas. As utopias políticas incluíam a democracia participativa, o presidencialismo plebiscitário e o parlamentarismo (Lamounier, 1990). As utopias econômicas incluíam a reafirmação e racionalização do estatismo desenvolvimentista, em uma versão distributiva, o neoliberalismo e o projeto de "integração competitiva", sendo este último usualmente desconsiderado pela literatura. A omissão deste ideário/utopia contribui para a visão simplista e 
tendente ao maniqueísmo que marca as interpretações sobre as políticas de liberalização do governo Collor e dos que o sucederam.

Nas eleições presidenciais de 1989 tais utopias estiveram em jogo, embora mescladas por apelos eleitorais que as obscureceram diante da maioria da população. A vitória de Fernando Collor, em dezembro daquele ano, pareceu definir, entre as alternativas, aquela que a sociedade brasileira trilharia dali em diante. O resultado eleitoral gerou a expectativa de que seriam revertidas pelo novo governo as condições negativas herdadas dos anos 1980 conforme um ideário liberalizante (indefinido entre as utopias neoliberal e de "integração competitiva") e pela afirmação do presidencialismo plebiscitário. Esta reversão, de fato, foi a principal tarefa a que se propôs o jovem presidente da República: estabilizar a moeda - antes de tudo - e promover reformas liberalizantes, "integrando o Brasil no Primeiro Mundo", foram os alvos principais do governo Collor.

Tratava-se de uma tarefa de grande magnitude, que exigia alta dose de poder político para ser realizada. Sua imagem pessoal, a legitimidade eleitoral da eleição em dois turnos e as normas constitucionais inerentes à Presidência da Republica davam a Collor um handicap muito favorável para a tarefa. Com efeito, o prestígio pessoal de Collor e a legitimidade da eleição direta acentuaram o considerável poder normativo da Presidência da República no sistema político instituído pela Constituição de 1988.

No entanto, o modo como construiu sua candidatura e desenvolveu a campanha eleitoral - com base em uma "empresa político-eleitoral" e não em uma coalizão político-partidária (Sallum Jr., Graeff e Lima, 1990) - não lhe dava bons alicerces para governar. É claro que Fernando Collor contava com a simpatia e o apoio do empresariado, sintonizado com seu liberalismo professo, mas isso não lhe supria a falta de apoio parlamentar organizado. Esta carência demandava do presidente eleito boa dose de arte política para converter as vantagens que tinha em poder político efetivo, de governo, para aprovar as reformas a que se propunha e, com isso, realizar a tarefa almejada. Não precisava de "arte política" em abstrato mas uma que fosse "ajustada às circunstâncias": tratava-se de exercer poder com base em um Estado fragilizado e dentro de regras e segundo valores políticos produzidos no Brasil pelo forte movimento de democratização política dos anos 1980 e pelo recente, mas ainda frágil, movimento de liberalização econômica. 
Como se sabe, o governo Collor não teve pleno sucesso em realizar seus objetivos. O governo mesmo foi interrompido por uma crise política - da qual não trataremos aqui - que redundou no impeachment do presidente da República. Este final prematuro não significa, porém, que tenha fracassado completamente, que não tenha avançado na realização de alguns de seus objetivos. Ou que não tenha dado contribuição relevante para a superação da crise de Estado em que surgiu.

Foi em sua política de "integração ao Primeiro Mundo" que ocorreram os avanços mais decisivos, embora muito menores do que os pretendidos. É dela que tratarei aqui, da reorientação econômica e externa do Estado que o governo Collor promoveu e deixou legados duradouros no Brasil contemporâneo. Deixarei de lado algumas iniciativas reformistas que não foram implementadas por falta de condições políticas e/ou por inépcia, como a reforma da administração pública. Com efeito, as políticas de orientação liberal aqui examinadas só dependiam do exercício do Poder Executivo ou contavam com amplo apoio político dos partidos conservadores e de centro ou, então, foram aprovadas no período inicial de governo em que o Poder Executivo teve proeminência decisiva sobre o Congresso Nacional.

\section{IDEÁRIOS DA LIBERALIZAÇÃO}

O governo Fernando Collor gerou um conjunto de reformas econômicas liberalizantes que fixaram balizas importantes para superação da crise de hegemonia iniciada em 1983-84. Tais reformas fizeram contraponto ao padrão existente de desenvolvimento e não tiveram uma, como sublinha a maior parte da literatura, mas dupla inspiração: o receituário neoliberal e o projeto de "integração competitiva".

Há que sublinhar que o padrão de relação Estado/mercado vigente, ainda que deteriorado, encontrou defensores nas múltiplas agências econômicas do Estado e nos segmentos empresariais mais dependentes da proteção estatal. Assim, o velho desenvolvimentismo resistiu ao reformismo liberal, mas de forma localizada e fragmentada. O nacional-desenvolvimentismo não encontrou, porém, defensores no plano político. As forças políticas de esquerda (PT, PC do B, PCB etc.) e uma parte da centro-esquerda nacionalista (existente no PMDB e PDT) propugnavam não a sua continuidade mas sua renovação com inflexão à esquerda. Do que se tratava? Pelo que se depreende da campanha eleitoral de Luiz Inácio Lula da Silva, esta inflexão significava, por um lado, 
a "desprivatização do Estado", com o rompimento das articulações "espúrias" entre empresas estatais e empresas privadas; e, de outro, a reorientação das políticas de Estado para a distribuição da renda. Tratava-se de um ideário, uma utopia, a que se pode denominar "desenvolvimentismo estatista e distributivo".

A este ideário contrapunham-se os projetos liberalizantes. O ideário neoliberal, como se sabe, ganhou relevância no fim dos anos 1970 em função das dificuldades de superar a recessão e a inflação daquela década com os instrumentos "keynesianos" de gestão macroeconômica, instrumentos antes predominantes especialmente na Europa. Os governos da primeira-ministra Margareth Thatcher na Inglaterra e, depois, do presidente Ronald Reagan nos EUA adotaram uma gestão econômica de orientação monetarista, priorizando o combate à inflação em relação à preservação do emprego e dos rendimentos do trabalho, abandonando as diretrizes keynesianas. Aos poucos a política monetarista foi associada a outras propostas, como as da desregulação dos mercados, da redução dos gastos sociais e do intervencionismo do Estado, do equilíbrio das finanças públicas, do livre fluxo de capitais e de mercadorias, compondo - ou melhor, dando força política - ao neoliberalismo, doutrina existente, mas de pouca expressão, desde o após Segunda Guerra Mundial. Este neoliberalismo renovado disseminouse pelo mundo "ocidental" sob o impulso dos governos inglês e norte-americano e das agências econômicas multilaterais como o Fundo Monetário Internacional e o Banco Mundial. O reformismo neoliberal adotava (e adota) uma perspectiva puramente mercantil, que tinha em vista a produtividade e a rentabilidade do capital, tendo como horizonte uma economia globalizada.

O projeto de "integração competitiva" nasceu como reação à crise do Estado nacional-desenvolvimentista que, estrangulado pela dívida externa e por desequilíbrios fiscais, perdeu condições na década de 1980 de impulsionar o desenvolvimento brasileiro, fosse diretamente fosse por meio de suas empresas ${ }^{2}$. A ideia central contida no projeto de "integração competitiva" era de transferir para a iniciativa privada o centro motor do desenvolvimento brasileiro, reduzindo as funções empresariais do Estado e "abrindo" a economia brasileira para o Exterior. Não se propugnava, porém, um "ajuste" passivo aos dinamismos do capitalismo mundial; propunha-se, ao contrário, uma reestruturação do sistema produtivo brasileiro em vista de tornar a indústria brasileira competitiva no plano internacional. Daí a ênfase dos formuladores e 
difusores do projeto de "integração competitiva" na formulação e execução de políticas industriais que estimulassem o empresariado privado a agir nesta direção. Nisso ele se distinguia e se contrapunha ao ideário neoliberal.

O ideário da "integração competitiva" diferenciava-se do neoliberalismo também por ser, ao contrário dele, uma forma de nacionalismo não defensivo, mas de afirmação nacional no plano internacional. Como consequência, esta vertente liberal almeja um Estado "forte", com capacidade de comando sobre as atividades econômicas que se desenvolvem no seu território. Esta perspectiva esteve em sintonia intelectual com a reavaliação crítica do desenvolvimento industrial latinoamericano que começara a ser feita no âmbito da Comissão Econômica para a América Latina (CEPAL) desde o início dos anos 1980 (Fajnzylber, 1983). Segundo esta reavaliação, o próprio padrão latino-americano de industrialização tornara-se insustentável em função, de um lado, de seu caráter imitativo, incapaz de gerar inovações tecnológicas e, de outro, em função de seu caráter autárquico, à margem da extraordinária onda de inovações técnicas e de gestão que marcaram a "terceira revolução industrial". A despeito dessas críticas ao padrão latino-americano de industrialização serem bastante similares às veiculadas pelos neoliberais, reitero mais uma vez que, no plano propositivo (e mesmo no que se refere à maior ou menor animosidade em relação ao nacional-desenvolvimentismo), os dois ideários eram bem distintos ainda que o debate político-intelectual posterior tenha obscurecido tais diferenças.

Quais eram os portadores destes ideários? O estatismo distributivista teve como portadores nos anos 1980 os partidos de esquerda e parte do PMDB e, a partir do final da década, ele foi preservado como ideário só pela esquerda. Apesar da derrota de 1989, os partidos de esquerda o mantiveram como diretriz política que serviu, junto com o velho nacional-desenvolvimentismo protecionista, como casamata ideológica de resistência partidária, empresarial e da tecnoburocracia estatal ao reformismo liberal.

A grande imprensa e as elites empresariais adotaram na segunda metade dos anos 1980 uma perspectiva cada vez mais liberal, embora algo imprecisa, cujo núcleo era o combate ao estatismo. Denunciava-se o intervencionismo estatal nas relações mercantis, especialmente o controle de preços, e o desequilíbrio das finanças públicas, identificado como 
fonte primeira da inflação. No limite, especialmente entre os economistas, este liberalismo ganhava uma articulação mais definida e consistente, na forma de neoliberalismo.

No mesmo período, segunda metade dos anos 1980, ganhou força entre dirigentes e técnicos de alto nível das empresas estatais, especialmente do Banco Nacional de Desenvolvimento Econômico e Social (BNDES), uma perspectiva liberalizante, mas alternativa ao neoliberalismo, o ideário da "integração competitiva". No fim da década de 1980 ela se difundiu entre as elites empresariais, mas de forma limitada, servindo de plataforma político-intelectual para a organização, por uma fração da grande indústria paulista, do Instituto de Estudos do Desenvolvimento Industrial (IEDI).

Embora no governo Collor tenham tido curso principalmente políticas orientadas pelo ideário da "integração competitiva", parte importante das ações do Estado seguiram outra orientação, sendo algumas delas marcadas pela truculência (reforma administrativa) e/ou pela busca de efeitos midiáticos (a venda de "mansões", "carros oficiais" e outras "mordomias"). Ademais, mesmo iniciativas estatais claramente orientadas para a reorganização industrial do país tiveram, por vezes, sua execução tão afetada pelas dificuldades macroeconômicas e pela política de estabilização que elas acabaram se aproximando do figurino neoliberal. Por outro lado, algumas iniciativas que poderiam ser vinculadas mais claramente ao ideário neoliberal foram bloqueadas pelo Congresso.

De todo modo, ainda que não se possa examinar aqui as fontes intelectuais e políticas de cada iniciativa reformista, cabe sublinhar a presença dos dois ideários mencionados como fontes inspiradoras do reformismo liberal do governo Collor, ao menos para evitar a tendência muito usual de 'enquadrá-lo' um rótulo único, "neoliberal", o que pode facilitar a polarização política, mas simplifica e torna equivocada a reconstrução histórico-sociológica.

\section{A NOVA ESTRATÉGIA BRASILEIRA DE INSERÇÃO INTERNACIONAL}

As iniciativas liberalizantes ocorreram em vários domínios, tanto na relação do Estado com o sistema internacional como no plano doméstico. No plano externo houve uma reorientação estratégica muito importante e duradoura, conservando-se em linhas gerais até o presente. 
Recorde-se que o Brasil mantinha "tradicionalmente" relações externas politicamente distantes e, ultimamente, bastante conturbadas com a liderança do mundo Ocidental desenvolvido. Além da interrupção dos fluxos voluntários de capitais para o Brasil, decorrente da "crise da dívida", o governo Sarney recorrera por duas vezes à interrupção dos pagamentos devidos aos credores externos para evitar o esgotamento das reservas cambiais. O Brasil estava, pois, em moratória quando Collor tomou posse. Acrescente-se a isso a falta geral de sintonia entre a "onda liberalizante" que se expandia mundialmente sob a liderança política dos EUA e a política do governo brasileiro de defesa do mercado interno e da indústria nacional. Ainda que nos últimos dois anos do governo Sarney tivesse havido iniciativas de "racionalização" das barreiras tarifárias - que podem ser tomadas como antecedentes das mudanças ocorridas depois -, a economia brasileira era ainda muito fechada em relação ao Exterior. Com efeito, não haviam desaparecido a barreira não tarifária e a superproteção tarifária para a indústria nacional. Ademais, permaneciam os contenciosos com o governo norteamericano em relação à ausência de proteção no Brasil para as patentes industriais e quanto à reserva de mercado para a informática.

Este descompasso entre transformações internacionais e situação interna tornou-se tanto mais notável porque, ao final de 1989, fora derrubado o Muro de Berlim, que dividia a parte ocidental de Berlim da oriental, sinalizando a derrota do socialismo soviético. Na época, esta derrota parecia tornar "inevitável" a unificação econômica mundial, em moldes capitalistas e sob instituições econômicas liberais. No plano específico das ideias, o "Ocidente" também avançava no sentido de universalizar a perspectiva neoliberal. Naquele mesmo ano de 1989, um seminário acadêmico internacional, reunindo economistas especialistas em América Latina na capital dos EUA, definiu o "Consenso de Washington", conjunto de recomendações de política econômica, formuladas de uma perspectiva neoliberal, a serem adotadas pelos governos latino-americanos "responsáveis"3. O "Consenso de Washington" ganhou grande relevância em função dos movimentos e partidos "de esquerda" terem feito dele um ícone da "imposição das políticas neoliberais" pelos países centrais e organismos econômicos multilaterais.

Além das divergências pontuais, durante a Guerra Fria, a política externa brasileira seguira - grosso modo - a estratégia de manter a "autonomia pela distância", o que significara manter-se vinculada ao "Ocidente", mas com certo afastamento em relação ao seu país líder, os 
EUA, e não aceitar quaisquer regimes internacionais que pudessem congelar a hierarquia de poder existente no plano mundial e/ou restringir a liberdade de intervenção do Estado sobre a economia e a vida social (Fonseca Jr., 1998). Obviamente, essa orientação internacional reforçava o protecionismo do Estado-varguista em relação à economia nacional.

Embora a política externa brasileira tenha manifestado sinais de mudança que acompanharam a inflexão liberalizante da segunda metade da década de $1980^{4}$, foi a desagregação do socialismo de Estado que, destruindo os alicerces da Guerra Fria e a polarização Leste-Oeste, produziu impactos decisivos na política internacional e, consequentemente, obrigou a uma redefinição do posicionamento do Brasil no mundo.

Com efeito, a ruptura do paradigma ordenador da política internacional produzirá mudanças profundas na percepção que as elites brasileiras tinham das relações internacionais e das possibilidades de atuação do Brasil neste âmbito. Tais mudanças foram assimiladas pelo governo Collor que as traduziu em uma nova política de inserção internacional do Brasil. Com efeito, pelo menos desde 1990 passou a predominar, na cúpula do Ministério das Relações Exteriores e, de forma geral, na elite do corpo diplomático brasileiro, a percepção de que as novas circunstâncias internacionais não eram tanto uma ameaça como uma oportunidade para o Brasil; e que a nova situação de poder internacional não seria necessariamente unipolar, podendo surgir novas polarizações (Neves, 1993). Em função disso, mostraram-se favoráveis a que o país, ao invés de encolher-se, autarquicamente, dentro de suas fronteiras, se integrasse ativamente no plano internacional e participasse da construção da nova ordem internacional então em gestação, tentando projetar os valores e interesses do Brasil nas suas instituições e órgãos reguladores. Mais, a alta hierarquia do Itamaraty via este projeto de inserção externa como parte da estratégia brasileira de "integração competitiva" ao Primeiro Mundo, estratégia que teria nas "reformas" a sua dimensão interna (Azambuja, 1990; Lafer, 1993).

Dessa perspectiva, as novas circunstâncias internacionais - de polaridades indefinidas - teriam aberto espaço para a participação na ordem mundial de potências médias, pouco relevantes do ponto de vista militar, mas com outros "ativos" importantes na política internacional (Lafer e Fonseca Jr., 1997) ${ }^{5}$. Havia que apresentar o Brasil ao concerto mun- 
dial das nações como um país grande, com uma economia dinâmica, democrático e pacífico, sem inimigos nas suas fronteiras, capaz de absorver sem conflitos populações cultural e etnicamente distintas, com capacidade de negociação e assim por diante (Abnedur, 1997). Isso significava redefinir o nacionalismo de tipo defensivo que marcara a inserção internacional do país no período da Guerra-Fria. A nova postura do Itamaraty estava embebida também de nacionalismo, mas ele era afirmativo das reais ou supostas virtudes brasileiras, um nacionalismo que levava à participação, à competição, ao esforço para que o país se tornasse um global player, que pudesse participar de várias formas da construção e da gestão de uma nova ordem internacional.

Embora essa reorientação tenha envolvido controvérsias internas quanto à interpretação da situação internacional e, ainda que as táticas adotadas em várias situações tenham sido por vezes hesitantes e de sinais contrários ${ }^{6}$, aos poucos a nova orientação foi se firmando ${ }^{7}$.

Em termos concretos, a diplomacia brasileira movimentou-se em dois sentidos. De um lado, tentou reduzir ou eliminar os contenciosos com os poderes centrais - dívida externa, patentes farmacêuticas e energia nuclear - e, de outro, procurou ampliar o âmbito de ação da diplomacia brasileira pela participação destacada na discussão dos chamados "novos temas" da política externa - como meio ambiente e direitos humanos - e pelo reforço da posição econômica e política brasileira com a construção de um bloco regional com seus vizinhos do Cone Sul da América do Sul.

Houve progressos substanciais nos dois sentidos mencionados. Avançou-se bastante, embora não o suficiente, na renegociação da dívida externa. Isso ocorreu, saliente-se, não apenas em função do empenho do governo brasileiro, mas também das mudanças favoráveis ocorridas nas condições internacionais de financiamento. Com efeito, estas mudanças facilitaram a rearticulação externa. Especialmente o Plano Brady de renegociação da dívida externa, envolvendo descontos para as dívidas vencidas, abriu novo horizonte para os governos latinoamericanos (Cline, 1989). De início, o governo Collor não adotou o mesmo caminho de outros países latino-americanos e envolveu-se, no período em que Zélia Cardoso de Mello dirigiu o Ministério da Economia, em duras disputas com os credores externos. A equipe de Zélia tentou postergar o fim da moratória herdada do período Sarney e enfraquecer a posição dos bancos privados estrangeiros na negociação 
da dívida externa, isolando-os dos governos e instituições financeiras multilaterais. Não teve sucesso ${ }^{8}$. A partir de abril de 1991, a estratégia brasileira de renegociação mudou, já sob a orientação do novo ministro da Economia, Marcílio Marques Moreira, tornando-se mais ajustada aos padrões definidos pelos credores externos. Dentro dos novos padrões, parte da dívida externa foi renegociada com o FMI e com o Clube de Paris, no começo de 1992, restando finalizar a negociação com os credores privados, o que só ocorreu depois do término do governo Collor. Algo similar ocorreu com as patentes farmacêuticas e a propriedade industrial em geral. Com base na promessa de envio de um projeto de Código de Propriedade Industrial até março de 1991, o governo norte-americano suspendeu em julho de 1990 as sanções comerciais que decretara contra o Brasil em função da falta de respeito às patentes. Um novo Código de Propriedade Intelectual, porém, só foi aprovado em 1995.

Procurou-se eliminar também o "contencioso nuclear" do Brasil com as grandes potências, adotando-se inicialmente uma via intermediária entre a recusa e a aceitação do tratado de não-proliferação nuclear $(\mathrm{TNP})^{9}$. Isto foi feito por gestos, como o do fechamento do local de testes nucleares na Serra do Cachimbo, e pela assinatura de alguns compromissos básicos. Tais documentos envolveram uma redefinição das relações do Brasil com a Argentina e destes com as potências nucleares. Os acordos foram facilitados pelo enfraquecimento econômico de ambos os países, duramente atingidos pelas consequências da crise da dívida externa, e pela reorientação política em relação ao mundo desenvolvido decorrente das eleições de Carlos Menem e Fernando Collor. Argentina e Brasil deixaram de ter como objetivo a produção autônoma de energia nuclear para fixarem-se apenas em garantir o acesso a tais tecnologias e a seu uso pacífico ${ }^{10}$. Isso permitiu a assinatura, em novembro de 1990, da Declaração sobre Política Nuclear Comum Brasileiro-Argentina, pelos presidentes Collor e Menem, pela qual se estabeleceu o Sistema Comum de Contabilidade e Controle (SCCC) de aplicação a todas as atividades nucleares dos dois países e se previram negociações com a AIEA para um acordo conjunto de salvaguardas baseado no SCCC. Com isso se reconhecia que, caso não fosse assegurada a transparência nos programas nucleares dos dois países, aumentariam as restrições internacionais para acesso à tecnologia sensível.

Na sequência, os dois países procuram garantir o acesso às tecnologias sensíveis e a continuidade das pesquisas nucleares que realizavam 
para fins pacíficos (o que incluía a realizada pela Marinha sobre propulsão nuclear para submarinos), assinando vários tratados em que mantêm sua posição tradicional contrária à assinatura do Tratado de Não-Proliferação (TNT), embora aderindo indiretamente a seus termos. Em 1991 foram assinados, em Guadalajara, o Acordo BrasilArgentina para o Uso Exclusivamente Pacífico da Energia Nuclear e, em Viena, o Acordo Quatripartite entre Brasil, Argentina, Agência Brasileiro-Argentina de Contabilidade e Controle (ABACC) e a Agência Internacional de Energia Atômica. No acordo de Guadalajara reafirma-se o propósito exclusivamente pacífico do uso de todo o material e de todas as instalações nucleares sob jurisdição de cada país, resguardando inclusive as pesquisas nucleares que a Marinha brasileira fazia sobre propulsão de submarinos, e também se inclui o compromisso de não-realização de explosões nucleares, ainda que para fins pacíficos. $\mathrm{O}$ Acordo Quatripartite, por sua vez, permitiu o controle de todas as atividades nucleares desenvolvidas nos dois países por uma agência de controle de ambos e pela AIEA.

Por último, Brasil e Argentina resolveram ratificar o Tratado de Tlatelolco (1967), que comprometia todos os países da América Latina com a não-proliferação, por meio de emenda apresentada em 1992 por alguns países latino-americanos, inclusive o Brasil, sobre as responsabilidades da Organização para a Proscrição de Armas Nucleares na América Latina (OPANAL). Este conjunto de iniciativas na área nuclear firmou internacionalmente a imagem do Brasil como país pacífico e, em termos específicos, facilitou bastante o acesso às "tecnologias sensíveis" para empresas e projetos brasileiros.

Como tais movimentos mostram, o reposicionamento do Brasil em relação às grandes potências e aos regimes internacionais envolveu também uma redefinição da posição brasileira em relação à Argentina, e vice-versa. Com efeito, neste realinhamento estratégico a Argentina deixa de ser tomada como adversária potencial; passa à condição de possível aliada e associada. Isso teve implicações militares: não só pelos acordos mencionados a propósito da energia nuclear; também pelo reposicionamento das tropas brasileiras, que foram transferidas do sul do país, fronteira com a Argentina, para outras regiões distantes de lá.

Eliminando, parcial ou totalmente, este conjunto de contenciosos internacionais, a diplomacia brasileira pôde avançar de forma mais enfática na busca de maior participação na construção/gestão da nova or- 
dem internacional. Destaca-se aqui uma iniciativa: o Brasil foi sede ${ }^{11}$, em junho de 1992, da Conferência das Nações Unidas sobre o Meio Ambiente e Desenvolvimento, reunião que gerou um conjunto de documentos que "definem um quadro jurídico para a cooperação internacional de importância fundamental"12. Nesta conferência, a Rio-92, erigiu-se o desenvolvimento sustentável como paradigma para a busca do crescimento econômico, o que fixava a preservação ambiental como limite à exploração econômica da natureza. Com esta e outras iniciativas o Itamaraty buscou participar dos chamados novos temas da agenda internacional, colocando o Brasil na vanguarda do processo de construção de regimes internacionais. No caso específico da proteção ambiental, o governo brasileiro afirmou-se, adicionalmente, como ator responsável em relação a seus próprios recursos naturais, a Amazônia antes de tudo.

Não há dúvida, porém, de que o elemento-chave da redefinição da estratégia brasileira em relação aos países vizinhos foi o Brasil ter criado com eles uma União Aduaneira. Já em 1990, Brasil e a Argentina assinaram a Ata de Buenos Aires, pela qual se comprometem a construir uma união alfandegária em pouco tempo. Em 1991, o Brasil e a Argentina, acompanhados do Uruguai e Paraguai, constituíram o MERCOSUL como espaço econômico regional a ser convertido em União Aduaneira no final de 1994. Este compromisso foi mesmo uma mudança extraordinária na estratégia brasileira, um marco do novo nacionalismo afirmativo. Ao assinar este acordo, o Brasil deu passo decisivo para ampliar seu espaço privilegiado de expansão econômica e reforçar sua posição no plano internacional. Selou-se aí um compromisso que transformava o principal adversário regional do Brasil, a Argentina, em país associado no plano econômico com possibilidade de converter-se em associado político. Reforçava-se o "nacional" pela aliança regional tendo em vista não só a ampliação "além fronteiras" do espaço econômico "interno" mas também a participação mais ampla do país no cenário internacional. Mas, note-se, pretendia-se ampliar o espaço econômico brasileiro não só para as empresas nacionais; o espaço econômico mais amplo visava atrair para cá as empresas multinacionais e abocanhar com isso uma porção relativa maior do sistema produtivo mundial.

Ademais, adotando a nova estratégia de inserção externa, o Brasil redefiniu-se como pretendente a participante ativo (com o máximo de proeminência possível a uma "potência média") na construção e ges- 
tão da nova ordem internacional, o que incluía seu contexto geopolítico latino-americano - neste caso em competição com a tradicional liderança política norte-americana na região.

\section{O REFORMISMO ECONÔMICO LIBERAL}

No plano doméstico, os elementos-chave das reformas liberalizantes desencadeadas pelo governo Collor foram a nova política industrial e de comércio exterior, a liberalização dos fluxos financeiros com o Exterior e a política de privatização.

A nova política industrial e de comércio exterior envolveu, em primeiro lugar, o fim das restrições não tarifárias para as importações e exportações e, em segundo lugar, a Política Industrial e de Comércio Exterior (PICE), lançada em julho de 1990 e consolidada com o Programa Brasileiro de Qualidade e Produtividade (PBQP), lançado em novembro de 1990, e o Programa de Competitividade Industrial (PCI), editado em fevereiro de $1991^{13}$.

No que se refere às restrições não tarifárias, as mudanças foram drásticas. Collor eliminou todo o poder discricionário do governo para autorizar exportações e licenciar importações; pôs fim à lista de cerca de 1500 produtos que eram de importação proibida para reservar o mercado à produção nacional; e acabou todas as isenções e reduções de tarifas de importações - cuja concessão era objeto central dos grupos empresariais de pressão - à exceção das existentes para a Zona Franca de Manaus e algumas poucas mais. Paralelamente, foram fechadas a CACEX e a CPA, órgãos que cuidavam de todos as restrições e incentivos eliminados, e suas funções - diminuídas e transformadas - foram transferidas ao Departamento de Comércio Exterior, subordinado ao Ministério da Economia. Com isso, transformava-se radicalmente a política de comércio exterior de "substituição de importações" do Estado Varguista; não se gerava uma nova política, mas se dava o primeiro passo para isso.

A eliminação das restrições não tarifárias teve seu complemento na Política Industrial e de Comércio Exterior (PICE) lançada em junho de 1990. Esta política não só tinha como referência o projeto de "integração competitiva" lançado pelo BNDES em meados da década de 1980, mas foi formulada na Secretaria de Comércio e Indústria do Ministério da Economia por uma equipe cujos quadros principais provinham daquele Banco e orientavam-se por aquela perspectiva ${ }^{14}$. Tratava-se de 
reforma liberalizante mas, como se viu anteriormente, de forma alguma neoliberal, a começar por ser uma política industrial - prática condenada pelo fundamentalismo de mercado - destinada a retomar a industrialização em moldes novos, que superassem o já anacrônico modelo de substituição de importações e a estagnação industrial da década anterior.

Esta estagnação produzira um enorme descompasso com a indústria dos países centrais tanto em relação ao ritmo de crescimento como aos seus respectivos padrões tecnológicos e organizacionais. A indústria de transformação brasileira cresceu apenas 0,2\% ao ano entre 1980 e 1990 - bem menos do que os Estados Unidos, para não falar do Leste da Ásia - e a maioria dos setores industriais brasileiros encontrava-se ao final do período "patentemente defasada frente ao estado das artes vigente no plano mundial. Só alguns ramos, produtores de commodities como celulose, minério de ferro, suco de laranja e alguns outros - mantinham-se atualizados. A indústria automobilística, muito particularmente, havia se retardado notoriamente a partir da segunda metade da década" (Castro, 1999:63).

Era em função dessa situação negativa que o governo se propunha a alterar a inserção internacional da economia e reordenar internamente o espaço ocupado pelo Estado e pelas empresas privadas, restringindo ao mínimo a face empresarial daquele e amplificando o papel da iniciativa privada, nacional e estrangeira, e sua capacidade de competição no plano internacional.

Em estudo acurado desse programa governamental, Fábio Erber descreveu-o como "uma 'pinça', combinando elementos de pressão sobre as empresas (chamados de 'políticas de competição') e de estímulo (as medidas de 'competitividade')" (Erber, 1991). A política de competição incluía, de um lado, a eliminação de controles estatais sobre as empresas e um programa de privatização e, de outro, um programa de redução progressiva das tarifas de importação em quatro etapas anuais, começando em 1991 e encerrando-se em 1994 ${ }^{15}$, de outro. Sublinhe-se que o programa original era, de fato, cauteloso: o ritmo de redução das tarifas não era uniforme, intensificando-se nas duas últimas etapas; e o grau maior de proteção era reservado aos setores intensivos em tecnologia (informática, química fina e máquinas-ferramenta com controle numérico). Quanto ao programa de "competitividade", ele incluía medidas nos planos estrutural, setorial e empresarial que estimulavam o 
investimento e a incorporação/adaptação de tecnologia. Como mostrou Erber, a política industrial e de comércio exterior era uma pinça de hastes desbalanceadas: uma política decidida de competição - tanto as privatizações das estatais não protegidas pela Constituição como a abertura comercial - implementada na cadência definida pelo Executivo e não dependente de recursos orçamentários; e uma política de competitividade sendo implementada de forma muito parcial e vagarosamente, dependendo de aprovação legislativa e de existência de recursos. Embora se possa argumentar - como fez Erber - que havia um desequilíbrio inerente ao próprio programa de reestruturação econômica - tendendo a ser desigual o ritmo de implementação das duas hastes da pinça na maioria das situações -, o que parece ter impedido o florescimento das melhores possibilidades do programa de renovação industrial foi ele ser sido implementado junto com uma política mal sucedida de estabilização, durante uma recessão industrial profunda e em meio à instabilidade política crescente ${ }^{16}$. A recessão e a incerteza quanto ao futuro amorteceram os estímulos à competitividade embutidos na própria abertura comercial que, além de pressionar a indústria com similares importados a preços menores, permitiria em circunstâncias não recessivas a renovação da indústria com máquinas e equipamentos importados a preços mais baixos. Além disso, o fracasso da política heterodoxa de estabilização e os maus resultados da política ortodoxa que a seguiu estimularam a equipe econômica a usar a competição externa como meio auxiliar de controle de preços. Com efeito, em fevereiro de 1992, o ministro da Economia determinou a antecipação em seis meses do cronograma previsto de redução de tarifas alfandegárias $^{17}$. Por fim, as dificuldades políticas do Executivo no Congresso tornaram muito difícil a aprovação de diplomas legais de interesse da Presidência, atrasando ou inviabilizando a implementação das iniciativas relativas à competitividade que em grande parte dependiam do Legislativo.

A redução das barreiras à importação de mercadorias foi acompanhada de uma gradual liberalização dos fluxos financeiros entre o Brasil e o Exterior. Este movimento seguiu à liberalização ocorrida na maioria dos países latino-americanos, embora no caso brasileiro ele tenha sido particularmente cauteloso. Recorde-se que no Brasil operavam dois mercados cambiais, o oficial, onde o governo tinha o monopólio das trocas, seja como comprador seja como vendedor, e o mercado "parale1o" onde se realizavam as operações não autorizadas. O governo pretendia com isso controlar os movimentos de capitais e a taxa de câm- 
bio. A escassez de divisas e as moratórias dos anos 1980 mostram que não teve muito sucesso. Nesta área, como na da liberalização comercial, as mudanças começaram no final do governo Sarney (dezembro de 1988). Instituiu-se neste período um Mercado de Câmbio Flutuante, em que o governo não operava, para abrigar pelo menos algumas operações de troca de moedas realizadas no "mercado paralelo". Com o governo Collor foi-se além. Por um lado, para atender principalmente aos fluxos de comércio exterior criou-se um Mercado de Câmbio Livre (de "dólar comercial"), no qual o governo mantinha o monopólio, mas deixou de ter a obrigação de atender todas as demandas de moeda estrangeira e, ao mesmo tempo, a obrigação de comprar as "sobras" de mercado. Por outro, foram feitas várias alterações no Mercado Flutuante para incluir aí uma grande variedade de transações com moedas estrangeiras (além das operações vinculadas ao turismo, heranças, transferências de patrimônio, transferências ao exterior de serviços prestados, pagamento ao exterior de despesas feitas com cartão de crédito etc.). Em 1991 abriu-se a possibilidade de investidores institucionais estrangeiros investirem no mercado acionário brasileiro e negociar no exterior títulos emitidos no Brasil. Esta abertura em relação ao investidores estrangeiros e, de forma geral, em relação aos movimentos de capitais com o Exterior culminou com a Carta Circular 2.259 do BC, de fevereiro de 1992, que criou no regulamento de câmbio um subtítulo específico para as contas que instituições de financeiras mantinham no Brasil (contas CC5). Ali ficou clara a conversibilidade de toda a moeda nacional depositada em contas CC5 de titularidade de bancos não residentes, seja qual for a origem. Quer dizer, os residentes no Brasil passaram a poder fazer depósitos em moeda nacional nessas contas, e o titular, um banco estrangeiro, poderia transformar esses depósitos em disponibilidades em dólares no exterior, passando pelo "mercado de câmbio flutuante". Estes depósitos independiam de se comprovar que o dinheiro tinha antes ingressado no país.

Todas estas alterações destinavam-se a facilitar a entrada de capitais estrangeiros no Brasil, inclusive pelo aumento das garantias de saída de capitais se os seus proprietários assim o desejassem ${ }^{18}$. Estas iniciativas de "abertura financeira", combinadas aos progressos na renegociação da dívida externa nos termos do Plano Brady (o acordo com o FMI data de janeiro de 1992), permitiram que o Brasil captasse parte do fluxo de capitais provenientes dos países centrais que voltaram a se aplicar na América Latina, depois de dez anos de retraimento (Naím, 1995). Com efeito, as reservas líquidas do Brasil em moeda estrangeira passaram 
de cerca de 9,5 bilhões de dólares entre 1988 e 1991 para aproximadamente 23,7 bilhões em 1992 e 32 bilhões em 1993.

Ao contrário da abertura do comércio exterior, a política de privatizações do governo Collor não pode ser especificamente vinculada ao projeto de "integração competitiva". Isso é tanto mais surpreendente porque a Comissão de Privatizações que dirigiu o processo era sediada no BNDES e tinha como presidente o dirigente máximo do banco onde se formulara nos anos 1980 a política de "integração competitiva" ${ }^{19}$. É verdade que, de forma similar ao programa heterodoxo inicial de estabilização, ela implicava sua versão inicial em "punição" ao "capital financeiro", pois obrigava as instituições financeiras a comprar "certificados de privatização", a serem usados como "moedas" nos leilões de venda das estatais. No entanto, as dificuldades de executar o programa de estabilização e a própria política de privatização levaram à redefinição das regras iniciais, o que reduziu o ônus previsto para as instituições financeiras e diminuiu, de forma drástica, o montante arrecadado com a venda de tais certificados. Além disso, procurou-se facilitar as vendas das empresas privatizáveis - quer dizer, das estatais que não contavam com proteção constitucional - autorizando-se o uso nos leilões de vários tipos de "moedas podres", títulos diversos da dívida pública com valor efetivo muito inferior ao valor de face ${ }^{20}$. Com isso, ao contrário do que se previa inicialmente, a privatização das empresas estatais no governo Collor acabou favorecendo os detentores de haveres financeiros, pois estes acabaram se "valorizando" ao serem convertidos em ativos produtivos.

Do ângulo do governo, o Estado "livrava-se", pela privatização, dos ônus de empresas deficitárias ou sem capacidade própria para se expandir, sem que a economia nacional as perdesse como unidades produtivas. De um lado, o resultado dos leilões permitia reduzir as dívidas do governo e, de outro, alienava para o capital privado, que se supunha ter melhores condições de gestão eficiente e de expansão, um patrimônio oneroso para as finanças públicas e sem capacidade de autorreprodução e expansão. Foi, pois, uma perspectiva fiscalista - considerada essencial para a estabilização - e genericamente privatista que orientou o processo de privatização. As privatizações não foram vinculadas a quaisquer projetos estatais de reestruturação produtiva dos setores ou complexos produtivos a que pertenciam as empresas estatais privatizadas ${ }^{21}$. Daí estar o programa mais próximo da orientação neoliberal do que do ideário da "integração competitiva". 
De qualquer maneira, o programa de privatizações no governo Collor teve resultados líquidos que impressionam, ainda que uma parte das ações adquiridas tenham permanecido sob o controle direto ou indireto do Estado (empresas estatais e fundos de pensão de seus empregados). Abateu-se dívida pública e, embora uma parte deste abatimento tenha sido "inflado", porque eram recebidas "moedas podres" dos compradores, resta pouca dúvida de que pelo menos algumas das estatais vendidas puderam, sob controle privado, recuperar-se e ampliar suas operações, enriquecendo ao invés de onerar o erário público. Foi o caso da Usiminas, da Aços Finos Piratini, da Siderúrgica Tubarão entre outros.

\section{Suporte Social ao Reformismo Liberal}

Que sustentação político-social tinham as reformas liberalizantes do governo Collor? É certo que as próprias ideias apresentadas por Collor ao longo da campanha eleitoral estavam em sintonia com a "inflexão liberal" que ocorrera entre as elites empresariais, na grande imprensa e na tecnoburocracia estatal principalmente a partir do fracasso do Plano Cruzado (1986) de estabilização. Mas sintonia com propostas não implica necessariamente apoio à sua implementação.

No caso em questão, contudo, pode-se dizer que, tanto as mudanças na política externa, especialmente a construção do MERCOSUL, como as políticas de liberalização econômica (abertura comercial e financeira e privatizações, por exemplo), contaram com suporte empresarial bastante grande. Chegou-se até, com boas razões, a descrever tal apoio como a formação de uma coalizão empresarial em torno de Collor e em favor das reformas liberalizantes (Kingstone, 1999, cap. 5). A coalizão sociopolítica liberalizante era, porém, mais ampla. Incluía tanto a maioria do empresariado - suas associações e a grande imprensa - como também parte da classe média ilustrada e segmentos do movimento sindical. O empresariado, embora se dividisse até o primeiro turno das eleições de 1989 entre vários candidatos "liberalizantes" (Collor, Mario Covas, Afif e outros), no segundo turno inclinou-se majoritariamente para Collor e forneceu copioso financiamento para sua campanha. E não apenas porque temia Lula e o Partido dos Trabalhadores, mas também porque as propostas de Collor, a despeito dos seus ataques às "elites" e à FIESP, sintonizavam em geral com a perspectiva empresarial. Assim, a vitória de Collor reforçou, pela conquista do poder político, a coalizão doméstica liberalizante. Esta tinha também pre- 
sença política entre os partidos de centro-direita, que se tinham congregado no "Centrão" durante a Assembleia Constituinte, e os de centro-esquerda, embora tais partidos tenham apoiado Lula no 2ㅇ turno das eleições de 1989. Depois das eleições, aquela parte do PSDB e do PMDB que havia experimentado, junto com o empresariado, uma "inflexão liberal", apoiou parte das iniciativas liberalizantes de Collor. No entanto, estas correntes liberalizantes de centro tenderam a se alinhar com os partidos de esquerda quando entenderam que estavam em jogo questões relativas à democratização da sociedade brasileira ${ }^{22}$.

Com efeito, passado o susto e a irritação causados pelas iniciativas estabilizadoras do início do mandato (retenção de ativos financeiros, congelamento etc.) e, à medida que os resultados da política econômica pareciam positivos ou, pelo menos, promissores, o empresariado e seus órgãos de representação passaram a apoiar claramente o governo Collor. Quer dizer, deixaram de manifestar as restrições que tinham acompanhado o seu assentimento e, mesmo adesão, ao programa inicial de privatização, de liberalização do comercio exterior e de reforma administrativa.

As diretrizes da nova política industrial e de comércio exterior e a assinatura do compromisso de construir o MERCOSUL como União Aduaneira coincidiram com as propostas dos grandes industriais reunidos no IEDI $^{23}$ e com as orientações das associações empresariais setoriais ${ }^{24}$. Com efeito, desde os anos finais da década de 1980, estas associações vinham se afastando da contínua busca de favores do Estado (até porque a crise do setor público reduziu drasticamente tal possibilidade), ainda que continuassem a pressionar o governo para que fossem preservadas e ampliadas as linhas setoriais de crédito do BNDES. Elas procuravam, ao invés de lutar favores, contribuir para a competitividade de seus associados, por meio de feiras de tecnologia, cursos de atualização tecnológica, informações estatísticas e contatos internacionais (Kingstone, 1999, cap. 4). Mais que isso, a abertura comercial ao Exterior contou com o assentimento não só das entidades empresariais como também de grande parte do empresariado, como mostrou pesquisa coordenada por Gesner de Oliveira em 1990/1991 (Oliveira, 1993:166-167). Segundo a pesquisa, 90\% consideravam a liberalização comercial correta, embora $52 \%$ a entendessem mal feita. Para $75 \%$ a redução de tarifas não comprometeria ou apenas um pouco os respectivos setores; $72 \%$ encorajariam os investimentos; $37 \%$ declararam estarem suas empresas já "ajustadas", 5,4\% disseram precisar de um ano 
para que isso ocorresse e $29 \%$, de até três anos - quer dizer, até o fim do programa de abertura, cerca de $81 \%$ das empresas esperavam estar "ajustadas" à nova situação. Talvez o ápice da adesão empresarial a Collor tenha sido marcado pela entusiástica acolhida que deram a seu discurso cerca de dois mil empresários reunidos no dia 30 de agosto de 1990 para a entrega dos prêmios dos "Maiores e Melhores" da revista Exame.

Entretanto, a simpatia com que o empresariado acompanhava a política econômica de Collor foi se convertendo, a partir dos últimos meses de 1990, em apreensão e distanciamento na medida em que se aprofundava a recessão, que a inflação intensificava seu ritmo ascendente e que a equipe econômica parecia se armar para novos experimentos heterodoxos. Com o Plano Collor II, lançado em 31 de janeiro de 1991, os temores se confirmaram e acentuou-se o distanciamento - e a oposição cada vez maior - do empresariado em relação à política econômica. Dizia-se que o governo Collor era politicamente esquizofrênico, o mais liberal e o mais intervencionista da história brasileira. Com a mudança de equipe econômica, em maio de 1991, desencadeada pela substituição de Zélia Cardoso de Mello por Marcílio Marques Moreira no comando do Ministério da Economia, houve certo alívio na tensão entre governo e empresariado. É que a alteração na equipe tornava improvável a adoção de novas medidas heterodoxas, além do que o novo ministro prometeu acabar com os controles administrativos de preços. No entanto, o rigor da ortodoxia fiscal e monetária implementada pela equipe montada pelo novo ministro da Economia acabou convertendo o empresariado em parte - muito moderada - da crescente oposição ao governo Collor. Mesmo sua antes tão festejada política de liberalização do comércio exterior passou ser alvo de críticas; pelo menos no que se referia ao ritmo acelerado com que vinha sendo executada.

Em suma, as restrições do empresariado em relação ao governo Collor concentraram-se no intervencionismo heterodoxo de sua primeira equipe econômica e nas políticas monetária e fiscal rígidas e recessivas que foram desenvolvidas ao longo de todo o governo, fosse na época em que Zélia Cardoso de Mello comandava a política econômica, fosse no período em que ela se tornou responsabilidade de Marcílio Marques Moreira. Desta maneira, o empresariado manteve durante todo o governo Collor uma relação ambivalente com suas políticas, de apoio às iniciativas liberalizantes e de restrição ao caráter intervencionista e/ou recessivo da política macroeconômica. As grandes empresas de 
comunicação de massa seguiram de forma geral a mesma orientação, embora com diferenças de ênfase.

As organizações sindicais de trabalhadores não aderiram com o entusiasmo do empresariado ao programa de reformas liberais, mas se conformaram pragmaticamente com ele. E não me refiro aqui apenas ao "sindicalismo de resultados", organizado na Força Sindical, central operária constituída em 1991 sob liderança de Luiz Antônio Medeiros, afinado com o liberalismo econômico e ligado ao governo Collor. Refiro-me à Central Única dos Trabalhadores (CUT), coluna vertebral do "novo sindicalismo", ligada ao PT e a outros partidos de esquerda. Embora colocada na defensiva pela recessão desencadeada pelo Plano Collor I, a CUT lutou fortemente para defender o valor dos salários e fez oposição à política macroeconômica e - sem muita efetividade - às privatizações; aceitou pragmaticamente, porém, as reformas liberais em curso.

Armando Boito Jr. observa - de uma perspectiva crítica de esquerda que a CUT trocou um sindicalismo de combate, o dos anos 1980, por um sindicalismo propositivo a partir do governo Collor, um sindicalismo que aceitava a realidade do capitalismo e pretendia apenas reformá-lo (Boito Jr., 1999, cap. IV). Na Plenária de Belo Horizonte (agosto/setembro de 1990), Jair Meneghelli, presidente da Central, apresentou a nova linha: "É preciso deixar de dizer apenas não e começar a dizer sim, a presentando propostas alternativas". Isso se materializou na proposta de "livre negociação salarial" com negociações por setores e por empresas e na decisão do IV Congresso Nacional da CUT (CONCUT), realizado em 1991, de apresentar "propostas de políticas de abrangência nacional" , como a política econômica, industrial, habitacional, de saúde, educação, previdência etc.. Ainda que de uma perspectiva socialista se possa criticar este tipo de sindicalismo propositivo, do ângulo das relações de poder social vigentes no Brasil ele era muito inovador pois trocava uma retórica, socialista, de viabilidade discutível, pela afirmação substancialmente "social-democrata" do direito e da capacidade de o operariado contribuir para moldar a sociedade capitalista brasileira - e não apenas de obter "resultados" em discussões pontuais sindicato/empresas. Sublinho que esta afirmação política tinha afinidade com os valores, de ampliação e universalização da cidadania, plasmados na Constituição de 1988. 
Em função dessas considerações, a CUT manteve uma posição ambígua em relação às várias propostas de realização de pacto social feitas pelo governo Collor. Dado que tais convites eram, de fato, maneiras de obter consentimento de trabalhadores e empresários para propostas do Executivo, compreende-se bem que não era mesmo possível dizer sim como a Central se propunha. No entanto, a partir de 1991 o Sindicato dos Metalúrgicos de São Bernardo e depois a própria CUT começaram a participar ativamente das câmaras setoriais criadas pelo Programa de Política Industrial e Comércio Exterior para definir políticas que permitissem reestruturar vários setores industriais recuperando a sua produção e elevando sua competitividade. Estas experiências de tipo social-democrata tiveram resultados variáveis, sendo a Câmara Setorial mais bem sucedida a da Indústria Automobilística (Arbix, 1997). O importante é que nestas câmaras articularam-se reformismo liberal orientado para a "integração competitiva" - e aprofundamento da democracia pela ascensão do operariado organizado ao plano das decisões de Estado, ainda que limitadas à esfera socioeconômica. As transformações político-ideológicas da CUT seguiram um curso reformista culminando em 1994 com a adesão ao projeto que estou denominando de "inserção competitiva" (Boito Jr., 1999:190-191) ${ }^{25}$.

Ainda que os atores-chave, no plano sociopolítico, apoiassem pelo menos uma parte das reformas liberalizantes implementadas pelo governo Collor, a instabilidade e o quadro recessivo do período reduziram severamente o impacto da abertura comercial sobre a indústria. Esta "modernizou-se" mais por mudanças organizacionais (downsizing) e pelo efeito das exigências da demanda (Ferraz, Kupper, e Haguenauer, 1997). Só mais tarde - depois do governo Collor - a abertura comercial e financeira produziria efeitos estruturais importantes no sistema produtivo brasileiro.

\section{CONCLUSÕES}

A reconstrução parcial da política brasileira de liberalização, particularmente daquela encetada durante o governo Collor, permitiu mostrar que as reformas liberais foram orientadas por duas diretrizes diferentes e não por uma apenas, como querem tanto partidários quanto críticos do neoliberalismo. Uma destas diretrizes, a de "integração competitiva", orientou de forma marcante a reorientação estratégica da política externa brasileira e também a reforma da política de comér- 
cio exterior, embora esta última sofresse grande impacto negativo da política de estabilização monetária.

A desorganização de vários ramos da administração do Estado, decorrente de uma reforma administrativa mal concebida e executada, e a privatização de parte das empresas do Estado, não devem ser tomadas como indicadores de uma estratégia consistente de promoção do Estado mínimo. Esta estratégia não existiu. Nem pode ser depreendida do reformismo liberal do governo Collor. $\mathrm{O}$ neoliberalismo influenciou apenas algumas das políticas reformistas, como a de privatização, e bloqueou uma atuação mais proeminente do BNDES na reestruturação produtiva que promoveria a competitividade da indústria brasileira.

O reformismo liberal que predominou no governo Collor - orientando tanto sua política externa como sua política de comércio exterior - não resultou em ou visou uma demissão da nação e do Estado em favor do mercado; tinha em vista, ao invés, a afirmação nacional pela elevação da capacidade de competição do país, seja na construção e gestão da nova ordem política internacional seja na economia de mercado que se expandia no plano mundial. A argumentação desenvolvida sublinhou, além disso, que o suporte social para a "integração competitiva" não se limitou ao empresariado mas incluiu também o sindicalismo operário de esquerda. Mais ainda, ela sugere que as câmaras setoriais, parte do processo de reestruturação produtiva, foram núcleos que articularam, embrionariamente, reformismo liberal e política social-democrata.

Esta apresentação, mesmo incompleta, de ideários e políticas que marcaram o período Collor, reconstituiu de forma mais complexa - espero - o processo de liberalização ocorrido no Brasil. Procurou enraizar ideários e políticas social e historicamente, mas o fez, bem o sei, esquematicamente. Seguramente isso exige trabalho complementar. A maior complexidade do quadro apresentado favorece também a comparação do caso brasileiro com outros processos de liberalização ocorridos na América Latina. Por último, vale sublinhar que as diversas políticas de liberalização tiveram destinos diversos - mantiveram-se e se renovaram, perderam provisoriamente relevância e depois foram retomadas ou simplesmente foram abandonadas. Com efeito, o processo de liberalização começou e continuou sendo complexo e disputado. É o que, em suma, este artigo pretendeu enfatizar.

(Recebido para publicação em março de 2011) (Aprovado para publicação em junho de 2011) 


\section{Brasilio Sallum Jr.}

\section{NOTAS}

1. Isso vale também pode para o trabalho de Kingstone (1999) - o mais completo, que eu saiba, sobre as relações entre o empresariado industrial e a política de liberalização econômica.

2. A exposição mais completa do ideário, de seu surgimento e evolução dentro do BNDES e impacto imediato encontra-se em Mourão (1994).

3. A expressão "Consenso de Washington" é de John Williamson. Ele redigiu o texto-síntese do seminário realizado em Washington nos dias 6 e 7 de novembro de 1989 (Williamson, 1990).

4. Na gestão Abreu Sodré, com Paulo de Tarso Flecha de Lima na Secretaria Geral do Itamaraty, no período final do governo Sarney, houve o empenho em elaborar uma "agenda positiva" com os EUA (Moreira, 2001:218-222).

5. A definição do Brasil como potência média, tornada dominante no Itamaraty, encontrou resistência entre os diplomatas simpáticos ao nacional-desenvolvimentismo: definir o país como potência média era a política do "Brasil pequeno" (Batista, 1993).

6. Ver, por exemplo, a crítica do embaixador Paulo Nogueira Batista à atuação brasileira-segundo ele, demasiado "pró-americana" - nas negociações finais da Rodada do Uruguai (Batista, 1993) e as reticências do embaixador brasileiro em Washington, Marcílio Marques Moreira, à posição de não-participação do Brasil na guerra contra o Iraque, desencadeada com autorização do ONU e sob a liderança dos EUA (Moreira, 2001).

7. Mesmo assim, só mais tarde, depois do fim do governo Collor, a reorientação da política exterior brasileira se consolidou plenamente (Vigevani, Oliveira e Cintra, 2003).

8. Já em agosto de 1990 Tomas Brady, secretário do Tesouro dos EUA, e Michel Camdessus, diretor-gerente do FMI, tornaram perfeitamente claro que as propostas do Brasil eram inaceitáveis.

9. Os parágrafos seguintes apoiam-se em Vargas (1997).

10. Segundo o então secretário-geral do Itamaraty: “O Brasil deverá empenhar-se crescentemente no sentido de tornar abertos os canais de acesso do país às tecnologias avançadas, através de propostas para tratamento multilateral mais transparente e de medidas de 'confidence building' do que são exemplo: os entendimentos na área nuclear entre Brasil e Argentina" (Azambuja, 1991:35).

11. A oferta inicial de o Brasil servir como sede da Conferência foi feita ainda no governo Sarney, mas a definição foi assegurada e implementada no período Collor.

12. Trata-se da Declaração do Rio, da Agenda 21, da Declaração sobre Florestas, a Convenção sobre o Clima e a Convenção sobre a Biodiversidade (Lafer, 1993).

13. Foi lançado também, em setembro de 1990, um programa intermediário definindo a política de "competitividade", o Programa de Apoio à Capacitação Tecnológica (PACT), com previsão de investimentos de US\$ 5 milhões em ciência e tecnologia até 1994.

14. O chefe do Departamento de Planejamento do BNDES, Luiz Paulo Velloso Lucas, tornou-se secretário de Indústria e Comércio do Ministério da Economia e teve para auxiliá-lo técnicos do Banco e da Petrobras. 


\section{Governo Collor: O Reformismo Liberal e a Nova Orientação da Política Externa...}

15. A tarifa média passaria de 35\% em 1990 para 20\% em 1994 e a dispersão entre elas seria reduzida, variando em 1994 entre zero e $40 \%$.

16. A hiperinflação foi bloqueada, mas não a inflação elevada; a recessão industrial foi profunda, -12\%, entre 1990 e 1992 (IBGE), embora tenha sido compensada nos dois anos subsequentes.

17. A redução tarifária prevista para janeiro de 1993 foi antecipada para outubro de 1992 e a de 1994 para julho de 1993.

18. Sobre a "abertura financeira" em seu conjunto, consultar Franco e Pinho Neto (2004) e Lann (2007).

19. Eduardo Modiano foi, no governo Collor, presidente do BNDES e da Comissão de Privatizações.

20. Sobre o programa e o processo de privatizações no governo Collor, consultar Prado (1993).

21. O que não implica que os empresários não tenham obedecido a estratégias empresariais e que estas não tenham moldado a forma da privatização de certos setores. É o que parece ter ocorrido em relação ao setor petroquímico.

22. A propósito da dupla vinculação dos partidos de centro à liberalização econômica e à democratização,, consultar Sallum Jr. e Casarões (2011).

23. Coincidiram até porque, como se viu, o IEDI formou-se sob o impulso do projeto de "integração competitiva" formulado no BNDES.

24. As associações empresariais são entidades formadas autonomamente por empresários de determinado setor ou setores próximos de âmbito nacional. São paralelas às organizações corporativas ligadas ao Estado, mas podem recobrir sindicatos setoriais. Associações importantes deste tipo são, entre outras, a ABINEE, da indústria de produtos elétricos e eletrônicos, a $\mathrm{ABIMAQ}$, das empresas produtores de máquinas e equipamentos, e a ANFAVEA, de fabricantes de veículo.

25. Boito Jr. remete com razão a perspectiva da CUT à ideologia neodesenvolvimentista ou neoestruturalista da CEPAL. Como indiquei anteriormemte as concepções neoestruturalistas estiveram na base da guinada em favor da reação ao neoliberalismo que resultou no projeto de "inserção competitiva", nascido nos anos 1980. 


\section{REFERÊNCIAS BIBLIOGRÁFICAS}

ABDENUER, Roberto. (1997), “A Política Externa Brasileira e o 'Sentimento de Exclusão'", in G. Fonseca Jr. e S. Castro (orgs.), Temas de Política Externa Brasileira II (2a ed.). Rio de Janeiro, Paz e Terra, vol. 1.

ARBIX, Glauco. (1997), “A Câmara Banida”, in G. Arbix e M. Zilbovicius (orgs.), De JKa FHC: A Reinvenção dos Carros. São Paulo, Scritta.

AZAMBUJA, Marcos C. (1990), A Política Externa do Governo Collor. Palestra proferida no Instituto de Estudos Avançados da Universidade São Paulo (USP). Série Documentos, IEA-USP, 19 de outubro.

. (1991), Conjuntura Internacional: Centros Mundiais de Poder. Conferência proferida durante o curso de Altos Estudos da Escola de Comando e Estado-Maior da Aeronáutica, e curso de Altos Estudos de Política e Estratégia da Escola Superior de Guerra, Rio de Janeiro, 23 e 24 de maio.

BATISTA, Paulo Nogueira. (1993), “A Política Externa de Collor: Modernização ou Retrocesso?". Política Externa, vol. 1, no 4.

BERGER, Suzanne e DORE, Robert (eds.). (1996), National Diversity and Global Capitalism. Ithaca, Cornell University Press.

BOITO Jr., Armando. (1999), Política Neoliberal e Sindicalismo no Brasil. São Paulo, Xamã.

CASTRO, Antônio Barros de. (1999), “O Lado Real do Real: O Debate e algumas Surpresas", in J. P. Almeida Magalhães et alii. (org.), Vinte Anos de Política Econômica. Rio de Janeiro, Contraponto.

CLINE, William. (1989), "From Baker Plan to Brady Plan", in I. Husain e I. Diwan (eds.), Dealing with the Debt Crisis. Washington, D.C., World Bank Simposium.

EDWARDS, Sebastian. (1994), Crisis and Reform in Latin America: From Dispair to Hope. New York, World Bank/Oxford University Press.

ERBER, Fábio. (1991), "A Política Industrial e de Comércio Exterior: Uma Avaliação", in IPEA (org.), Perspectivas da Economia Brasileira, 1992. Brasília, IPEA, pp. 305-333.

FAJNZYLBER, Fernando. (1983), La Industrialização Trunca de America Latina. México, Nova Imagem.

FERRAZ, João Carlos; KUPPER, David e HAGUENAUER, Lia. (1997), Made in Brasil: Desafios Competitivos para a Indústria. Rio de Janeiro, Editora Campus.

FILGUERAS, Luiz. (2000), Historia do Plano Real. São Paulo, Ed. Boitempo.

FONSECA Jr., Gelson. (1998), A legitimidade e outras Questões Internacionais. São Paulo, Paz e Terra.

FRANCO, Gustavo e PINHO NETO, Demosthenes. (2004), A Desregulamentação da Conta de Capitais: Limitações Macroeconômicas e Regulatórias, texto preparado para o seminário "Aprimorando o mercado de câmbio brasileiro", promovido pela Bolsa de Mercadorias e Futuros (BM \& F), São Paulo, 4 de dezembro de 2003 (versão condensada de 2004).

HAGGARD, Steven. (1995), Developing Nations and the Politics of Global Integration. Washington, D.C., The Brokings Institution. 


\section{Governo Collor: O Reformismo Liberal e a Nova Orientação da Política Externa...}

KINGSTONE, Peter R. (1999), Crafting Coalitions for Reform. Pennsylvania, University Park, Penn State Press.

LAFER, Celso. (1993), “A Política Externa do Governo Collor". Política Externa, vol. I, no 4 .

; FONSECA JR., Celso. (1997), “Questões para a Diplomacia no Contexto Internacional das Polaridades Indefinidas (notas analíticas e algumas sugestões)", in G. Fonseca Jr. e S. H. Nabuco de Castro (orgs.), Temas de Política Externa Brasileira II (2a ed.). São Paulo, Paz e Terra, vol. 1.

LAMOUNIER, Bolivar. (1990), “Antecedentes, Riscos e Possibilidades do Governo Collor", in B. Lamounier (org.), De Geisel a Collor: O Balanço da Transição. São Paulo, IDESP, pp. 13-35.

MOREIRA, Marcílio M. (2001), Diplomacia, Política e Finanças. Rio de Janeiro, Objetiva.

MOURÃO, Julio O. F. (1994), “A Integração Competitiva e o Planejamento no Sistema BNDES". Revista do BNDES, vol. 1, № 2.

NAÍM, Moises. (1995), “Latin America in the Morning After”. Foreign Affairs, vol. 74, no 4.

NEVES, Carlos Augusto R. S. (1993), “O Brasil e o Futuro: Linhas para uma Presença do Brasil na Vida Internacional”. Política Externa, vol. 1, no 4.

OLIVEIRA, Gesner. (1993), “Condicionantes e Diretrizes de Política para a Abertura Comercial Brasileira”. Texto para a Discussão no 313, IPEA, Brasília.

OMAHE, Keneth. (1991), The Borderless World: Power and Strategy of Interlinked Economy. New York, Perennial.

PRADO, Sérgio. (1993), “Crise do Estado e Privatização: Limites da Visão Neoliberal”, in VV. AA. Crise Brasileira, Anos Oitenta e Governo Collor. São Paulo, DESEP (CUT)/ Instituto Cajamar.

SALLUM Jr., Brasilio; GRAEFF, Eduardo P. e LIMA, Elisabeth. (1990), “Eleições Presidenciais e a Crise do Sistema Partidário". Lua Nova, no 20, pp. 69-87.

SALLUM Jr., Brasilio e CASARÕES, Guilherme. (2011), “O Impeachment de Fernando Collor: A Literatura e o Processo". Lua Nova, no 82, pp. 163-200.

VARGAS, Everton Vieira. (1997), “Átomos na Integração: A Aproximação Brasil-Argentina no Campo Nuclear e a Construção do Mercosul". Revista Brasileira de Política Internacional, vol. 40, no 1 .

VIGEVANI, Tullo; OLIVEIRA, Marcelo F. de; CINTRA, Rodrigo. (2003), “Política Externa no Período FHC: A Busca de Autonomia pela Integração". Tempo Social, vol. 15, no 2 .

WILLIAMSON, John. (1990), “What Washington, D.C. Means by Policy Reform”, in J. Williamson (ed.), Latin American Adjustment: How Much Has Happened?. Washington D.C., Institute for International Economics. 


\author{
ABSTRACT \\ The Collor Administration: Liberal Reformism and the New Brazilian \\ Foreign Policy
}

This article discusses liberalization during the Fernando Collor Administration (1990-1992), seeking to demonstrate that the process was far more complex than the academic literature has acknowledged. The argument is that liberal reformism was dually inspired, namely by neoliberalism and the "competitive integration" project, and that it met resistance from both proponents of national developmentalism and its distributive version. It addition to schematically reconstructing these sets of ideals, the article discusses various state policies inspired by them, including foreign policy, foreign trade reform, privatization, etc. Finally, it seeks to identify the agents that sustained such policies and ideals. The article concludes with the overall results and suggestions for further research on the theme.

Key words: economic liberalization; foreign policy; Collor Administration

\title{
RÉSUMÉ
}

Gouvernement Collor: Le Réformisme Libéral et la Nouvelle Orientation de la Politique Extérieure Brésilienne

Dans cet article, on examine le processus de libéralisation pendant la période Collor pour chercher ensuite à montrer que ces mécanismes ont été bien plus complexes que ce que rapporte la littérature à leur sujet. On voit que le réformisme libéral a été le fruit d'une double inspiration - le néolibéralisme et le projet d'"intégration compétitive" - et s'est heurté à des résistances venant d'acteurs partisans d'un développementisme national persistant ou de la version redistributive de celui-ci. On a essayé de conceptualiser ces ensembles d'idées et de présenter plusieurs politiques d'État qui y ont puisé, comme ce fut le cas pour la politique extérieure, la réforme du commerce extérieur, la privatisation etc. On s'emploie enfin à identifier les agents qui ont soutenu ces politiques et ces idées et on conclut sur un résumé des résultats et des suggestions en vue d'autres recherches.

Mots-clés: libéralisation économique; politique extérieure; gouvernement Collor 